\title{
Perceived Noise Analysis for Offset Jets Applied to Commercial Supersonic Aircraft
}

\author{
Dennis L. Huff ${ }^{1}$, Brenda S. Henderson ${ }^{2}$, Jeffrey J. Berton ${ }^{3}$ and Jonathan A. Seidel. ${ }^{4}$ \\ NASA Glenn Research Center, Cleveland, Ohio, 44135
}

\begin{abstract}
A systems analysis was performed with experimental jet noise data, engine/aircraft performance codes and aircraft noise prediction codes to assess takeoff noise levels and mission range for conceptual supersonic commercial aircraft. A parametric study was done to identify viable engine cycles that meet NASA's $N+2$ goals for noise and performance. Model scale data from offset jets were used as input to the aircraft noise prediction code to determine the expected sound levels for the lateral certification point where jet noise dominates over all other noise sources. The noise predictions were used to determine the optimal orientation of the offset nozzles to minimize the noise at the lateral microphone location. An alternative takeoff procedure called "programmed lapse rate" was evaluated for noise reduction benefits. Results show there are two types of engines that provide acceptable mission range performance; one is a conventional mixed-flow turbofan and the other is a three-stream variable-cycle engine. Separate flow offset nozzles reduce the noise directed toward the thicker side of the outer flow stream, but have less benefit as the core nozzle pressure ratio is reduced. At the systems level for a three-engine $\mathrm{N}+2$ aircraft with full throttle takeoff, there is a 1.4 EPNdB margin to Chapter 3 noise regulations predicted for the lateral certification point (assuming jet noise dominates). With a $10 \%$ reduction in thrust just after clearing the runway, the margin increases to 5.5 EPNdB. Margins to Chapter 4 and Chapter 14 levels will depend on the cumulative split between the three certification points, but it appears that low specific thrust engines with a $10 \%$ reduction in thrust (programmed lapse rate) can come close to meeting Chapter 14 noise levels. Further noise reduction is possible with engine oversizing and derated takeoff, but more detailed mission studies are needed to investigate the range impacts as well as the practical limits for safety and takeoff regulations.
\end{abstract}

\section{Nomenclature}

$\begin{array}{ll}\text { A } & =\text { area } \\ \text { AAPL } & =\text { Aero-Acoustics Propulsion Laboratory } \\ \text { AAVP } & =\text { Advanced Air Vehicles Program } \\ \text { ANOPP } & =\text { Aircraft Noise Prediction Program } \\ \text { BPR } & =\text { bypass ratio } \\ \text { CST } & =\text { Commercial Supersonic Technology } \\ \text { DoD } & =\text { Department of Defense } \\ \text { DOE } & =\text { design of experiments } \\ \text { EPNL } & =\text { effective perceived noise level } \\ \text { EPNdB } & =\text { effective perceived noise level in decibels } \\ \text { FAR } & =\text { federal aviation regulation } \\ \text { FPR } & =\text { fan pressure ratio } \\ \text { GE } & =\text { General Electric } \\ \text { HFJER } & =\text { high flow jet exit rig } \\ \text { HSR } & =\text { High Speed Research program }\end{array}$

${ }^{1}$ Research Aerospace Engineer, Acoustics Branch, MS 54-3, AIAA Associate Fellow.

${ }^{2}$ Research Aerospace Engineer, Acoustics Branch, MS 54-3, AIAA Associate Fellow.

${ }^{3}$ Aerospace Engineer, Propulsion Systems Analysis Branch, MS 5-11, AIAA Senior Member.

${ }^{4}$ Aerospace Engineer, Propulsion Systems Analysis Branch, MS 5-11, AIAA Senior Member. 


$\begin{array}{ll}\text { IVP } & =\text { inverted velocity profile } \\ \text { M } & =\text { Mach } \\ \text { MFTF } & =\text { mixed-flow turbofan } \\ \text { NATR } & =\text { nozzle acoustic test rig } \\ \text { NPSS } & =\text { numerical propulsion system simulation } \\ \text { NPR } & =\text { nozzle pressure ratio } \\ \text { NTR } & =\text { nozzle temperature ratio } \\ \text { OPR } & =\text { overall pressure ratio } \\ \text { PLdB } & =\text { perceived noise level in decibels } \\ \text { PLR } & =\text { programmed lapse rate } \\ \text { PNL } & =\text { perceived noise level } \\ \text { PNLT } & =\text { tone-corrected perceived noise level } \\ \text { SPL } & =\text { sound pressure level } \\ \text { TOGW } & =\text { takeoff gross weight } \\ \text { VCE } & =\text { variable cycle engine }\end{array}$

Subscripts

$\begin{array}{ll}\mathrm{b} & =\text { bypass } \\ \mathrm{c} & =\text { core } \\ \mathrm{fj} & =\text { free jet } \\ \mathrm{t} & =\text { tertiary }\end{array}$

\section{Introduction}

$\mathrm{T}$

The Commercial Supersonic Technology (CST) project of the Advanced Air Vehicles Program (AAVP) at NASA is developing enabling technologies for supersonic aircraft to meet environmental and performance requirements. One of the technology challenges is to minimize the propulsion noise for low-boom aircraft. The goal is to develop design tools and innovative concepts for integrated supersonic propulsion systems with cumulative aircraft noise levels of 10 EPNdB under ICAO Chapter 4 regulations. A summary of NASA's supersonic aircraft technology research goals is shown in Table 1. ${ }^{1}$ The overall approach for supersonic aircraft development is to start with smaller payloads for the near-term $(\mathrm{N}+1)$ and increase the aircraft size over time $(\mathrm{N}+2$ and N+3), while simultaneously meeting environmental and performance goals. There are specific goals for noise, emissions and performance across the entire aircraft mission for takeoff, cruise and landing.

Table 1. Research goals for supersonic aircraft. ${ }^{1}$

\begin{tabular}{|c|c|c|c|}
\hline & $\begin{array}{c}\mathrm{N}+1 \\
\text { supersonic business class aircraft } \\
(2015)\end{array}$ & $\begin{array}{c}\mathrm{N}+2 \\
\text { small supersonic airliner } \\
(2020)\end{array}$ & $\begin{array}{c}\mathrm{N}+3 \\
\text { efficient multi-Mach aircraft } \\
\text { (beyond 2030) }\end{array}$ \\
\hline \multicolumn{4}{|c|}{ Environmental goals } \\
\hline Sonic boom & 65 to 70 PLdB & 65 to $70 \mathrm{PLdB}$ & $\begin{array}{l}65 \text { to } 70 \text { PLdB } \\
\text { low-boom flight } \\
75 \text { to } 80 \text { PLdB } \\
\text { overwater flight }\end{array}$ \\
\hline $\begin{array}{l}\text { Airport noise } \\
\quad \text { (cum below Chapter 4) }\end{array}$ & Meet with margin & $10 \mathrm{EPNdB}$ & 10 to $20 \mathrm{EPNdB}$ \\
\hline $\begin{array}{l}\text { Cruise emissions } \\
\quad \text { (cruise } \mathrm{NO}_{\mathrm{x}} \mathrm{g} / \mathrm{kg} \text { of fuel) }\end{array}$ & Equivalent to subsonic & $<10$ & $\begin{array}{l}<5 \text { and particulate and } \\
\text { water vapor mitigation }\end{array}$ \\
\hline \multicolumn{4}{|c|}{ Performance goals } \\
\hline Cruise speed & Mach 1.6 to 1.8 & Mach 1.6 to 1.8 & Mach 1.3 to 2.0 \\
\hline Range (n mi) & 4000 & 4000 & 4000 to 5500 \\
\hline Payload (passengers) & 6 to 20 & 35 to 70 & 100 to 200 \\
\hline $\begin{array}{l}\text { Fuel efficiency } \\
\quad \text { (pass-miles per lb of fuel) }\end{array}$ & 1.0 & 3.0 & 3.5 to 4.5 \\
\hline
\end{tabular}

American Institute of Aeronautics and Astronautics 
Another major challenge for commercial supersonic aircraft is the continued success of noise reduction for the subsonic fleet and the subsequent increased stringency of international noise regulations. The recent approval of Chapter 14 noise regulations by ICAO requires new subsonic aircraft in a comparable $\mathrm{N}+2$ vehicle class to be 7 EPNdB (effective perceived noise level) cum under Chapter 4 levels by 2017. ${ }^{2}$ In addition, there needs to be sufficient margin below the regulations to account for uncertainties and growth versions of aircraft. This will likely require even more aggressive noise reduction goals for supersonic aircraft.

The difficulty of simultaneously meeting the noise, emissions and performance goals makes supersonic engines good candidates for variable or adaptive cycles. For example, a third flow stream is being considered that effectively increases the bypass ratio of the engine during takeoff. A benefit of this approach is to reduce takeoff community noise and still meet engine performance requirements for high-speed cruise. Recent NASA propulsion system studies for an $\mathrm{N}+2$ commercial supersonic transport have focused primarily on the use of Variable Cycle Engine (VCE) adaptations to a military-style Mixed-Flow TurboFan (MFTF). This focus originated from early conceptual studies supporting NASA's High Speed Research (HSR) Program, which identified a variable tip-fan engine architecture as an engine cycle with promise to overcome evolving commercial acoustic certification challenges. ${ }^{3,4}$ Reinforcing this pursuit of engine architecture are engine-company and U.S. Department of Defense (DoD) investments in VCE technologies for future military propulsion systems. The NASA VCE studies parametrically build upon broader investigations in MFTF propulsion trades spanning a range in engine Bypass Ratio (BPR) and Fan Pressure Ratio (FPR). ${ }^{5,6,7}$

Supersonic engines, however, must balance the drag associated with higher BPR (low specific thrust) cycles in achieving both acceptable cruise performance and acceptable take-off noise levels. Inlets and nozzles designed for optimum supersonic cruise must meet diverse inlet airflow demands and nozzle expansion ratios to attain successful performance across a large range of flight Mach numbers. In addition, there is a desire for commercial supersonic vehicles to achieve a high fineness ratio, which impacts the outer mold lines of the inlet, engine nacelle, and nozzle to reduce the sonic-boom during overland supersonic flight. This dichotomy between the optimum engine for takeoff noise and the optimum engine for cruise efficiency and sonic boom necessitates a compromise in acceptable fuel economy and/or weight to achieve commercial acceptability.

This paper investigates the benefits of offset jets for N+2 supersonic vehicles. An engine parametric study was conducted that identifies acceptable design criteria for meeting performance and noise goals. Model scale experimental data from recent offset nozzle tests are used to investigate perceived noise reduction of jet noise at full scale for takeoff conditions. NASA's ANOPP (Aircraft Noise Prediction Program) code is used to "fly" the engine through a representative trajectory to assess lateral takeoff noise, which is a certification point where jet noise dominates over other noise sources. The azimuthal angles of the offset nozzles are varied to determine the best orientation on the three-engine aircraft for minimizing perceived noise. The impact of an alternative takeoff procedure called "programmed lapse rate" (PLR) is also investigated.

\section{Engine Parametric Study}

A parametric study of a MFTF and VCE was conducted to investigate aircraft performance (mission range) trades with takeoff noise levels. A jet noise component-EPNL was calculated as the acoustic figure of merit using a maximum power flyover. A reference study vehicle was supplied by the NASA Langley Research Center that is representative of the Lockheed Martin "1044" aircraft, which has three engines embodying low-boom weight and aerodynamic characteristics. ${ }^{8}$ The NASA reference vehicle has a Takeoff Gross Weight (TOGW) of 290,000 pounds, a design range of approximately 4200 nautical miles, a cruise speed of Mach 1.70, and meets commercial Federal Aviation Regulations (FARs) with practical limits (e.g. engine-out sizing, field-length requirements, reasonable take-off and landing speeds, etc.).

A parametric Design of Experiments (DOE) was performed to 1) narrow the VCE ranges of interest relative to acoustic and mission range performance, and 2) compare the results to a conventional twostream cycle MFTF. The NASA parametric VCE uses an independent tip-fan mounted atop the main fan and exhausted separately (Fig. 1). The main engine closely resembles a

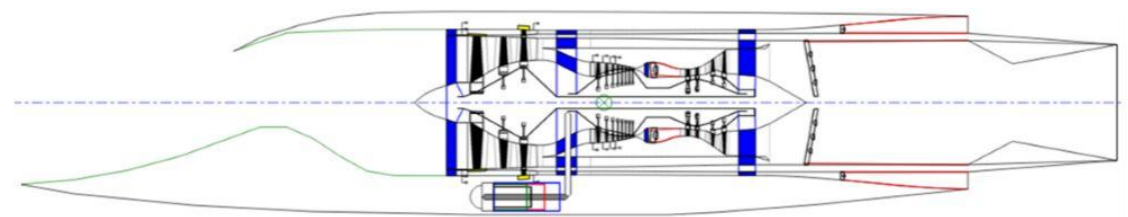

Figure 1. Variable Cycle Engine for N+2 NASA reference vehicle. 
military-style two-spool MFTF, with additional VCE features of cooling flow modulation to help balance work between the spools during part-power operation. The tip-fan flow is modulated throughout the mission envelope of speed and altitude, optimizing maximum installed net thrust for max-power conditions and minimum specific fuel consumption for part-power. A simple algorithm was used within the Numerical Propulsion System Simulation (NPSS) code to conduct an installed propulsion optimization which included inlet performance (pressure recovery and installed drag) as well as aft-body nozzle installation drag.

The results from the DOE are shown in Fig. 2 and serve as the impetus for acoustic trades in the two design regions of interest. Symbols depict variations in engine design parameters impacting takeoff acoustics and mission range performance (such as throttle ratios and FPR). The noise levels are for only the jet noise component which dominates for takeoff (lateral) and is given in EPNdB. The absolute numbers are not given at this point and there is a 2 EPNdB difference between grid lines, with increasing levels of noise and FPR in the positive y-direction. The range is given on the $\mathrm{x}$-axis in terms of nautical miles. The FPR values vary from 1.85 to 4.05 from the bottom to the top of the plot, respectively. Lower FPR can be achieved with a single-stage fan, which reduces the weight of the engine resulting in improved range. The black solid symbols are for a MFTF with two cycle flow streams $\left(\mathrm{BPR}_{\mathrm{t}} \sim 0\right)$ terminating in a single exhaust, and the color open symbols are for a three-stream VCE terminating in two exhaust flows (mixed core and separate tertiary flow). Each symbol represents a different combination of engine Overall Pressure Ratio (OPR), main engine bypass and throttle ratio, and design bypass ratio of the third stream $\left(\mathrm{BPR}_{\mathrm{t}}\right)$. For higher FPR, the VCE performs best over the MFTF. For lower FPRs using only a single-stage fan, the MFTF and VCE are similar, with the exception of a few points where the MFTF has a slightly higher range approaching 4300 nautical miles.

The results indicate there are two types of engines with maxima for performance: a low

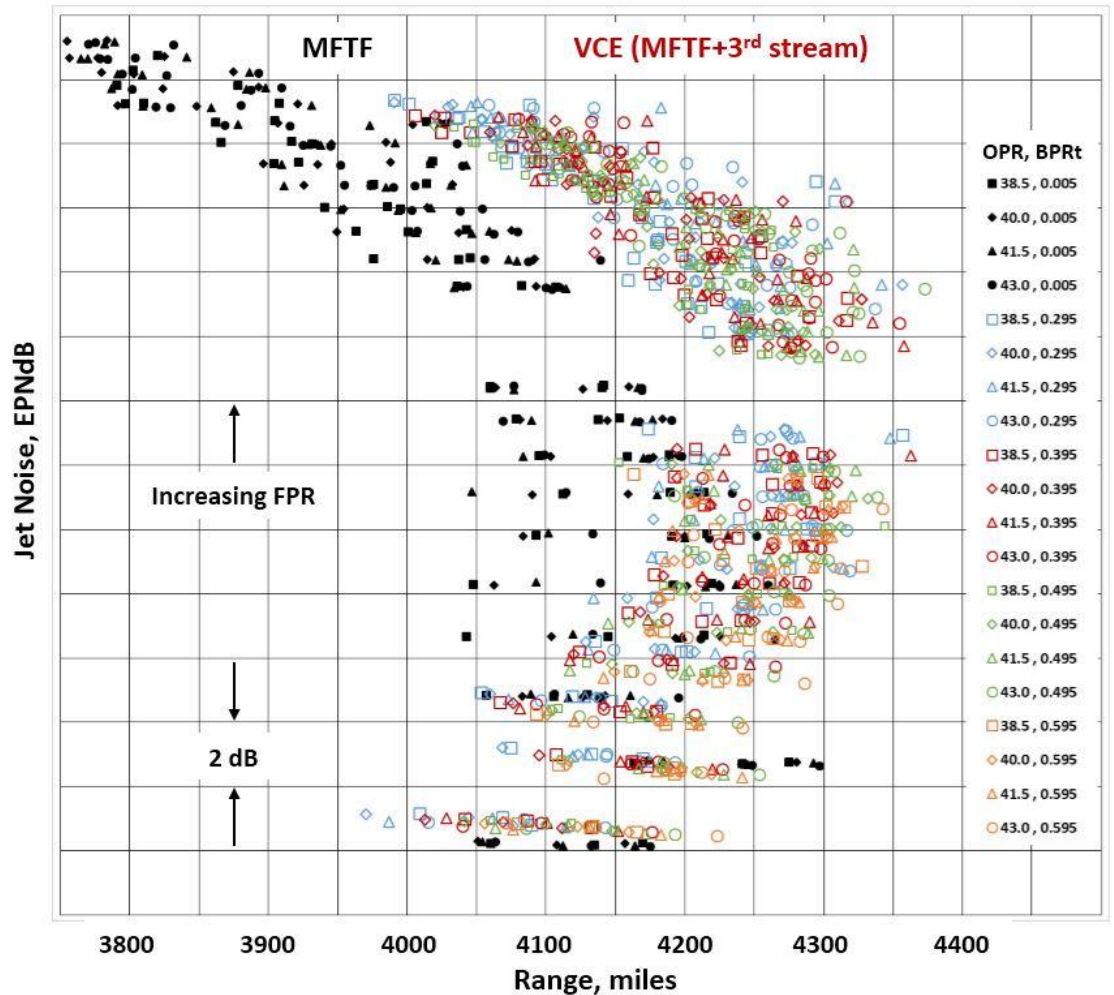

Figure 2. DOE comparisons of takeoff jet noise versus aircraft mission range for MFTF and VCE engines using the NASA N+2 reference aircraft configuration.

FPR (single-stage) MFTF with two cycle flow streams and a higher FPR VCE with three-streams. The latter is predicted to have jet noise levels that are higher by 8 to $10 \mathrm{EPNdB}$ with only a 100 mile range advantage over a MFTF. While this lower specific thrust engine seems to be an obvious choice, the associated larger diameter nozzles could be a concern for sonic boom and needs to be evaluated. Even though both types of engines exceed the target range goals stated in Table 1, there are missions where a modest increase in range enables additional routes. Therefore, noise reduction technologies such as offset nozzles or inverted velocity profiles are needed for VCEs. The remainder of the discussion in this paper will focus on finding ways to reduce jet noise through optimal azimuthal orientations of separate flow offset nozzles over a range of flow conditions that are applicable to a VCE, and compare the results with axisymmetric nozzles. 


\section{Experiments}

\section{A. Offset Nozzles}

Offset nozzles have been investigated as a way to reduce jet noise by introducing an asymmetric noise field in the azimuthal direction. Papamoschou ${ }^{9}$ found that offsetting the bypass stream of a supersonic jet decreases the Mach wave radiation on the thicker side of the jet due to increased mixing and a reduced potential core length. Subsequent experiments and analyses have been done to better understand the noise reduction mechanisms for offset streams including s-ducts and turning vanes for diverting the flow. For the current study, the tertiary nozzle was offset relative to the core and bypass nozzles for a separate flow exhaust.

Tests were conducted using model-scale nozzles with and without offset streams. Experiments were performed in the Aero-Acoustic Propulsion Laboratory (AAPL) at the NASA Glenn Research Center (Fig. 3). The AAPL is an acoustically-treated geodesic dome that provides a free-field for noise measurements. The AAPL contains the Nozzle Acoustic Test Rig (NATR), which produces a free jet to simulate forward flight and contains the High Flow Jet Exit Rig (HFJER), a three-stream jet engine simulator capable of replicating most commercial turbofan engine temperatures and pressures. Acoustic measurements were made with the far-field array shown in Fig. 3. The array contains microphones located on a constant radius arc covering polar angles between 45 and 160 degrees, where angles greater than 90 degrees are in the downstream direction relative to the nozzle inlet. All data were corrected for atmospheric

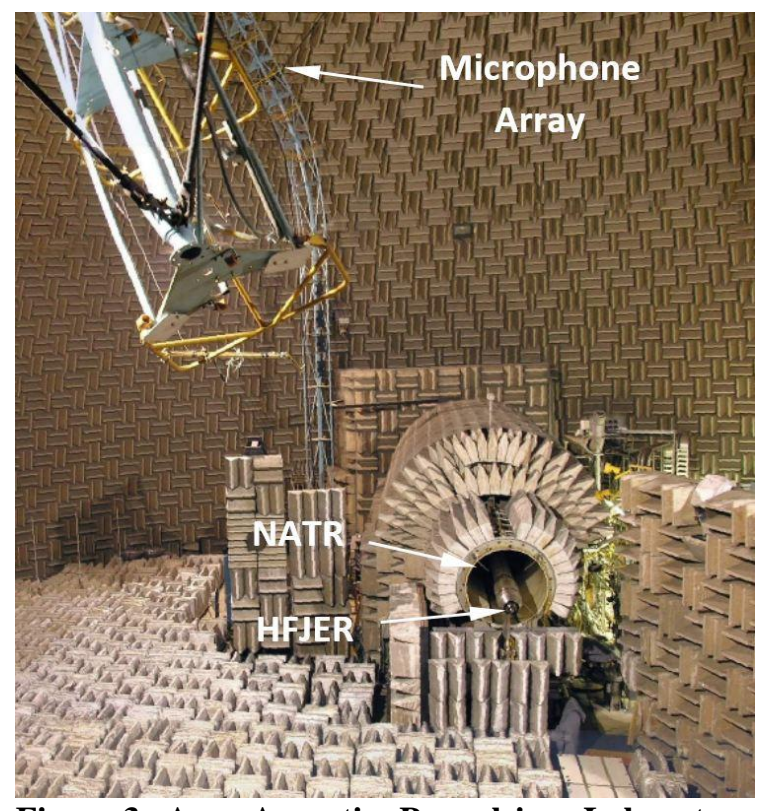

Figure 3. Aero-Acoustic Propulsion Laboratory (AAPL) with the Nozzle Acoustic Test Rig (NATR) and High-Flow Jet Exit Rig (HFJER). absorption and free jet shear layer effects.

The axisymmetric investigations used the separate flow nozzle system shown in Fig. 4(a) with the range of tertiary-to-core area ratios $\left(A_{t} / A_{c}\right)$ and bypass-to-core area ratios $\left(A_{b} / A_{c}\right)$. All test configurations used a core nozzle exit diameter of 5.2-inches with an area of 10.8 square-inches. For the offset configurations, an offset duct was used upstream of the bypass nozzle (Fig. 4(b)). The offset duct produced a 0.156-inch offset of the tertiary-nozzle centerline relative to the centerlines of the core and bypass nozzles. The offset nozzle installation in HFJER is

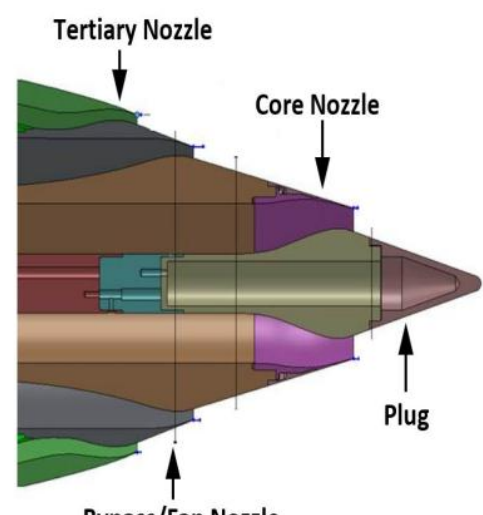

Bypass/Fan Nozzle

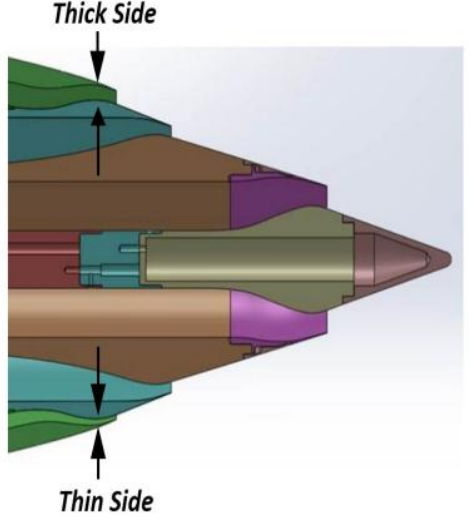

(b)

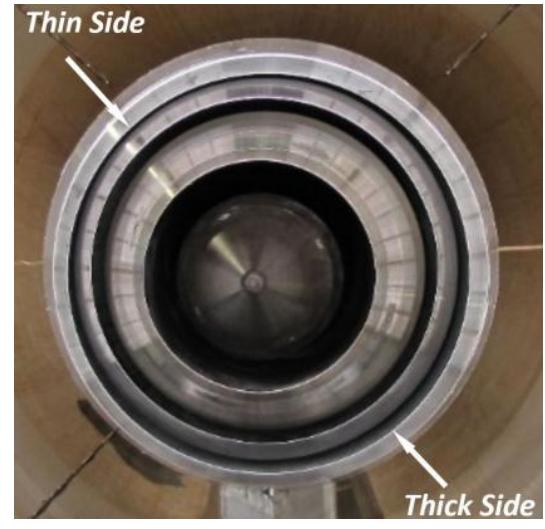

Figure 5. Offset nozzles installed in HFJER and NATR viewed from downstream.

Figure 4. Nozzles used for three-stream experiments, (a) axisymmetric and (b) offset. 
shown in Fig. 5. For the case shown, the thin side is oriented toward the far-field microphone array shown in Fig. 3. The nozzles were clocked 180-degrees to orient the thick side toward the microphone array to measure the difference in noise due to azimuthal variation.

Table 2 summarizes the range of set points used in the experiment for each stream. The nozzle pressure ratio, NPR, is the ratio of the jet stagnation pressure to the ambient pressure. The nozzle temperature ratio, NTR, is the ratio of the jet stagnation temperature to the ambient temperature. Subscripts $c, b$, and $t$ indicate core, bypass, and tertiary, respectively. Data were acquired for free jet Mach numbers, $M_{\mathrm{fj}}$, of 0 and 0.3 that simulate flight.

Table 2. Test conditions for three-stream jets.

\begin{tabular}{|c|c|c|c|}
\hline $\mathrm{NPR}_{\mathrm{c}}$ & $\mathrm{NPR}_{\mathrm{b}}$ & $\mathrm{NPR}_{\mathrm{t}}$ & $\mathrm{NTR}_{\mathrm{c}}$ \\
\hline 1.80 & 1.60 & $1.00-1.80$ & 1.00 \\
\hline 1.80 & 1.50 & $1.00-1.80$ & 3.00 \\
\hline 1.50 & 1.80 & $1.00-2.10$ & 3.00 \\
\hline 1.80 & 1.80 & $1.00-2.10$ & 3.00 \\
\hline 2.10 & 1.80 & $1.00-2.10$ & 3.00 \\
\hline 2.10 & 2.10 & $1.00-2.10$ & 3.00 \\
\hline 2.30 & 1.80 & $1.00-2.10$ & 3.00 \\
\hline 2.30 & 2.30 & $1.00-2.10$ & 3.00 \\
\hline
\end{tabular}

\section{B. Acoustic Data}

Sample acoustic spectra in terms of Sound Pressure Level (SPL) obtained on the thick side and thin side of the jet for offset nozzles are shown in Fig. 6 for a supersonic core $\left(\mathrm{NPR}_{\mathrm{c}}=2.1\right)$ and in Fig. 7 for a subsonic core $\left(\mathrm{NPR}_{\mathrm{c}}\right.$ $=1.8$ ). For both cases, $\mathrm{NPR}_{\mathrm{b}}=$ $1.8, \mathrm{NTR}_{\mathrm{c}}=3.0, \mathrm{NTR}_{\mathrm{b}}=1.25, \mathrm{M}_{\mathrm{fj}}$ $=0.3$, and the pressure ratio of the third stream $\left(N P R_{t}\right)$ is varied. The model data were scaled to the takeoff thrust required for the Lockheed Martin "1044" aircraft. The spectra are one-foot lossless for the peak jet noise angle which occurs $140^{\circ}$ relative to the inlet axis. Part (a) is for $A_{b} / A_{c}=1.0$ and part (b) is for $A_{b} / A_{c}=2.5$. The solid lines are for data taken with the thick side oriented toward the microphones, and the dashed lines are for the thin side toward the microphones. The black lines are cases with $\mathrm{NPR}_{\mathrm{t}}=1$, which is the same as a dual-stream jet with axisymmetric nozzles. The differences between the solid and dashed black lines are attributed to the third stream nozzle being installed around the dual-stream jet even though it is shutoff.

For the case with a supersonic

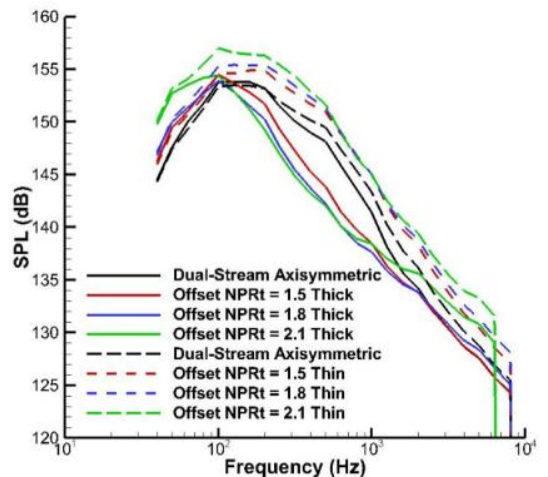

(a)

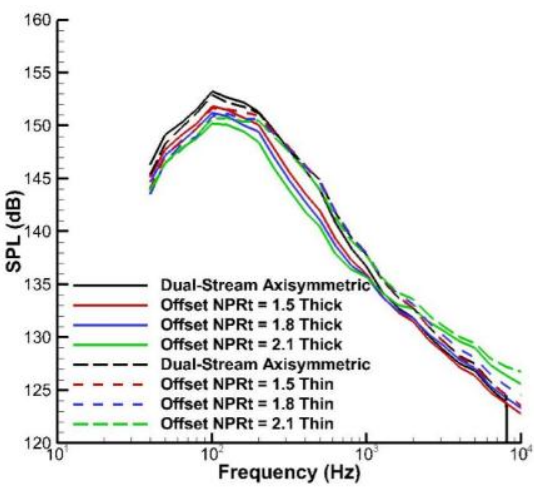

(b)

Figure 6. Single engine full-scale one-third octave spectra for offset nozzles with NPRc $=2.1, \mathrm{NPR}_{\mathrm{b}}=1.8, \mathrm{NTR}_{\mathrm{c}}=3.0, \mathrm{NTR}_{\mathrm{b}}=1.25, \mathrm{M}_{\mathrm{fj}}=0.3$ at peak jet noise angle $\left(140^{\circ}\right),(a) A_{b} / A_{c}=1.0$ and (b) $A_{b} / A_{c}=2.5$.
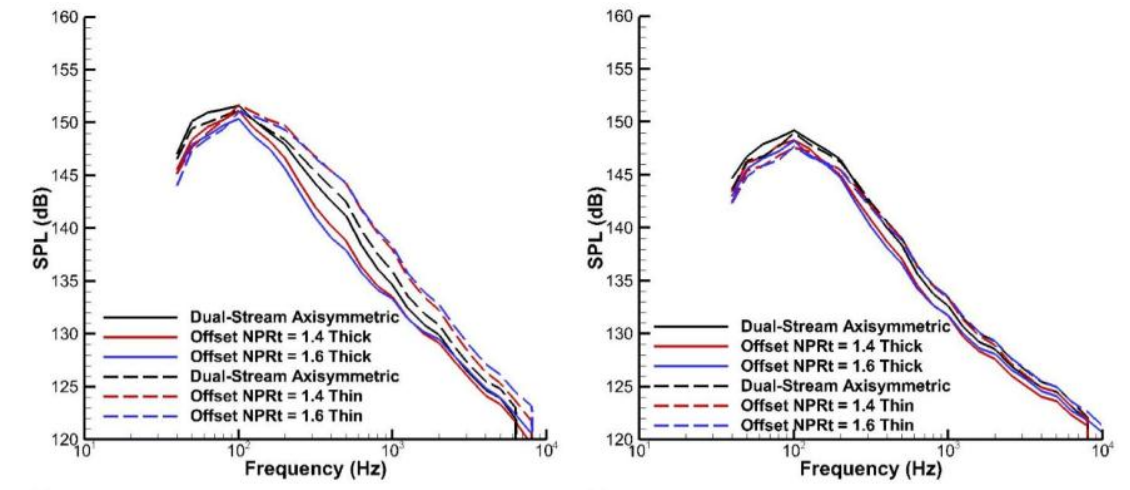
(a)

(b)

Figure 7. Single engine full-scale one-third octave spectra for offset nozzles with $\mathrm{NPRc}=1.8, \mathrm{NPR}_{\mathrm{b}}=1.8, \mathrm{NTR}_{\mathrm{c}}=3.0, \mathrm{NTR}_{\mathrm{b}}=1.25, \mathrm{M}_{\mathrm{fj}}=0.3$ at peak jet noise angle $\left(140^{\circ}\right),(a) A_{b} / A_{c}=1.0$ and $(b) A_{b} / A_{c}=2.5$. 
core, there is noise reduction for the peak relative to a dual-stream axisymmetric jet for both azimuthal angles when $\mathrm{A}_{\mathrm{b}} / \mathrm{A}_{\mathrm{c}}=2.5$ (Fig. 6(b)). For $\mathrm{A}_{\mathrm{b}} / \mathrm{A}_{\mathrm{c}}=1.0$, the noise levels increase on the thin side and decrease on the thick side (Fig. 6(a)). When the core flow is subsonic, the benefits of the offset nozzles are reduced and the spectra are closer to a dual-stream jet as $A_{b} / A_{c}$ is increased (Fig. 7(b)). The overall noise levels are lower for $\mathrm{NPR}_{c}=1.8$ compared to $\mathrm{NPR}_{\mathrm{c}}=2.1$. A complete description of the acoustic data can be found in Ref. 10.

\section{Predictions}

\section{A. Aircraft Noise}

The acoustic data show noise reduction at the peak directivity angle of the jet. But reductions in SPL do not always translate into significant reductions of perceived noise from the aircraft. The aircraft system noise metric chosen for this analysis is the Effective Perceived Noise Level, or EPNL, defined in the ICAO Annex $16^{11}$ or its FAA equivalent, Part 36. ${ }^{12}$ The basis of the EPNL is the Perceived Noise Level (PNL). The PNL is a weighted noise rating computed from one-third octave band SPL, with particular emphasis given to levels at frequencies between $1 \mathrm{kHz}$ and $10 \mathrm{kHz}$. An additional tone correction penalty is added to the PNL, forming the PNLT noise metric. During a noise certification test, spectral acoustic measurements are made as an airplane flies past three certification noise observation monitors on the ground (shown in Fig. 8). Spectra are measured at half-second time intervals at each noise observation station. From these, PNLs and PNLTs are computed. The EPNL is determined from a PNLT versus time history. Thus the EPNL is a metric sensitive to level, frequency, tone content, and duration of a single airplane flyover event. In noise certification parlance, the cumulative ("cum"), or algebraic sum of the three certification EPNLs is often used to capture all three measurements. In this study, only the lateral EPNL is considered. The lateral microphone location lies along a sideline parallel to the runway displaced $1476-\mathrm{ft}$ from the extended runway centerline. It is assumed to be located along the sideline across from the location where the airplane reaches an altitude of 1000 -ft above field elevation (i.e., the point where ground attenuation effects diminish and where maximum lateral noise is typically observed).

The lossless experimental jet spectra are manipulated to account for sizing effects from model scale to full scale, as

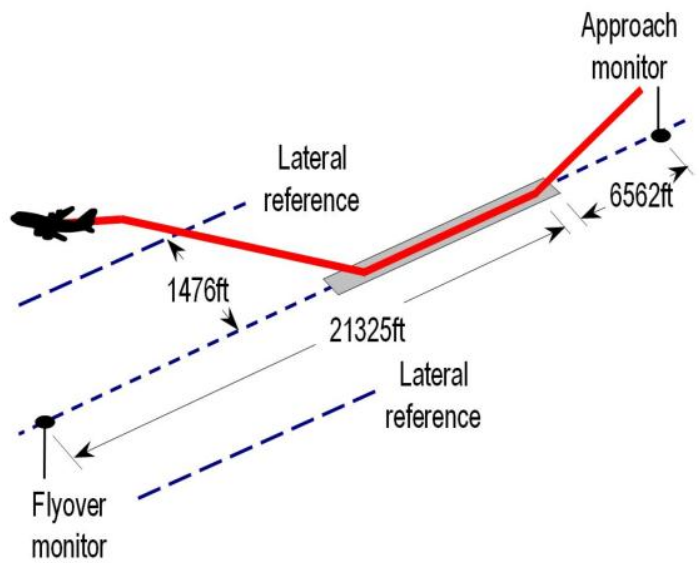

Figure 8. Noise certification monitor arrangements relative to takeoff and landing flight paths.

well as for Doppler and convection effects of forward flight. The scaled data are used as input into ANOPP ${ }^{13,14}$ as user-supplied noise on a one-foot arc. ANOPP propagates the lossless spectra to the lateral observer on the ground, accounting for atmospheric absorption, spherical spreading, ground reflections, and lateral attenuation effects.

The airplane trajectory is prescribed in the ANOPP simulation. Vector geometry analyses for the airplane are performed within ANOPP as functions of source time. From these spectra, ANOPP computes several noise metrics of interest as functions of observer time. The EPNL certification noise metric is computed from the noise vs. time history at each observer as prescribed in Refs. 11 and 12. 


\section{B. EPNL Values}

Predicting the absolute levels of noise from an aircraft is a challenge due to the many uncertainties associated with the noise sources and the propagation path to the microphone. For this reason, noise "deltas" are commonly used to compare configurations rather than relying on absolute values. In 2001, NASA conducted flight tests with a Learjet aircraft to evaluate the noise reduction from engines with chevron nozzles. ${ }^{15}$ The Lear 25 had two GE CJ610-6 turbojet engines that were clearly the dominant noise source for high power flyovers. During the $500-\mathrm{ft}$ altitude flyovers, one engine was throttled back while the other engine was used to test various nozzle configurations over a range of throttle settings. Prior to the flight tests, model scale nozzles were built and tested in the NATR. This provided a good opportunity to compare the absolute noise levels between model scale tests simulating forward flight, and flight tests for an aircraft with a dominant jet noise source.

The data from the model tests were processed to simulate a flyover. The PNL time histories comparing the model data and

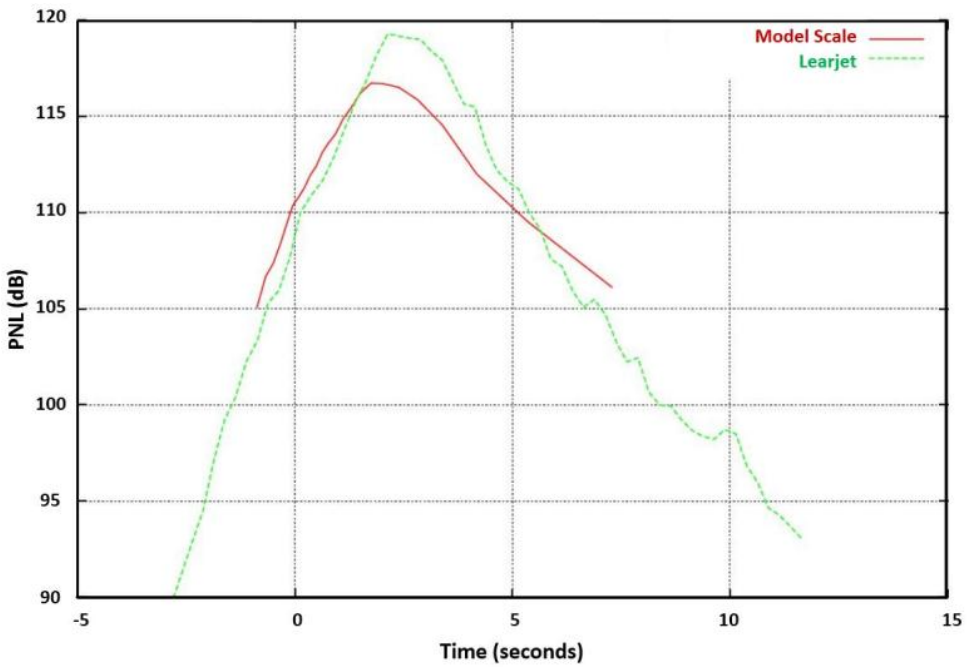

Figure 9. Perceived noise levels for model scale nozzles tested in NATR and flight tests measurements on a Learjet. the flight data are shown in Fig. 9. The peak levels from the model scale data are lower than the flight data by about $2 \mathrm{~dB}$ and the falloff is shallower. The differences are attributed to shear layer corrections and source distribution assumptions associated with the processing of the model data. It is also possible that installation effects and other noise sources could be increasing the noise levels from the flight data. On an EPNL basis, the model data simulated flyover was 112.1 EPNdB and the Learjet data was 113.5 EPNdB. Similar differences were found for test cases using chevron nozzles. For the purposes of this paper, a $2 \mathrm{EPNdB}$ offset will be applied to all model scale data to estimate the expected absolute jet noise levels. A more detailed investigation of installation and source noise corrections from model to flight data needs to be done to improve estimates for absolute noise levels.

\section{Programmed Lapse Rate (PLR)}

Historically takeoff noise levels for high specific thrust engines are dominated by the jet. The most effective way to reduce noise is to reduce the thrust from the engine to lower the jet exit velocity. Commercial aircraft use a cutback procedure just after takeoff to reduce the community noise while the aircraft is climbing at low altitudes. During the High Speed Research (HSR) program in the 1990s, an operational procedure called "programmed lapse rate" was investigated to reduce the takeoff noise closer to the airport. ${ }^{3,16,17}$ The idea behind PLR is to use the computer control for the engines to begin throttling back just after clearing the runway to reduce noise for the lateral microphones. Current FAA regulations prevent a pilot from performing this maneuver due to safety concerns, but it might be possible for an advanced control system to safely

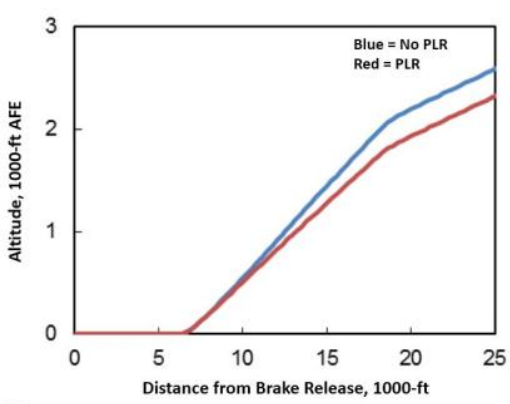

(a)

Figure 10. Comparison of a regulation takeoff using a noise abatement throttle cutback (blue) and an advanced takeoff combining a cutback with an unconventional programmed lapse rate procedure (red), (a) aircraft altitude, (b) net thrust fraction.

maintain sufficient airspeed and climb rates similar to the existing FAA regulation governing Automatic Takeoff 
Thrust Control System (Part-25, Subpart-E 25.904). If permitted, this procedure offers the greatest potential for takeoff engine noise reduction.

An example of how PLR could be implemented for takeoff is shown in Fig. 10. The blue lines show a standard takeoff procedure that meets regulations and uses a throttle cutback to reduce the engine thrust by the time the aircraft reaches the flyover monitor (Fig. 8). The red lines show the results from an additional cutback from a PLR procedure that reduces the aircraft altitude (Fig. 10(a)) and the engine thrust (Fig. 10(b)). At the lateral monitor location, which occurs just over 10,000-ft from brake release, the loss in altitude is minimal while the reduction in engine thrust is $10 \%$. By the time the aircraft reaches the flyover monitor (21,325-ft from brake release), the throttle setting is similar for both procedures and the aircraft continues its takeoff climb. The actual reduction in engine thrust for PLR will depend on the specific aircraft. It is likely that the allowable reduction will be in the order of 5 to 10 percent. For the current study, a 10 percent PLR is investigated for lateral noise levels and compared to standard takeoff procedures.

\section{Noise Assessments}

The acoustic data from the offset nozzles were used to predict the jet noise levels for a 3-engine aircraft emulating the Lockheed Martin "1044" $\mathrm{N}+2$ aircraft (Fig. 11(a)). The TOGW of the aircraft was increased slightly from the 290,000 pounds used in the NASA engine

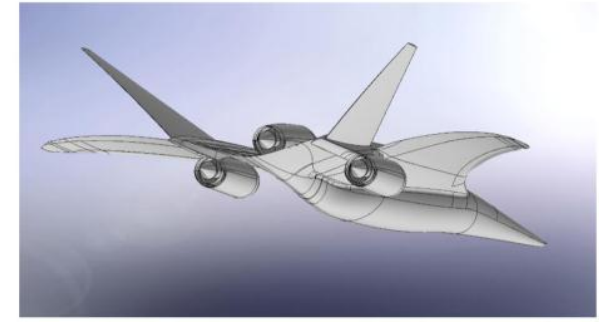

(a)
Figure 11. Aircraft noise assessments for offset nozzles, (a) Lockheed-Martin "1044" aircraft and (b) nozzle orientations from pilot's view to minimize jet noise toward the lateral microphones.

parametric study to 320,000 pounds used by Lockheed Martin and General Electric. ${ }^{8}$ The nozzles were oriented to minimize the noise levels at the lateral microphone for takeoff. A linear variation in azimuthal noise directivity was assumed by using the thick side (quietest) and thin side (loudest) acoustic spectra as input to ANOPP and interpolating for other angles. A study was conducted to determine the best orientation of each engine nozzle for an aircraft with three engines. Results show that the nozzles for the left engine should have the thick side located 65degrees clockwise relative to a straight down pilot's view, the center engine should have the thick side straight down, and the right engine should be symmetric with the left engine and the thick side rotated 65-degrees counterclockwise (Fig. 11(b)).

The acoustic data shown in Figs. 6 and 7 were used as input to ANOPP and "flown" using a takeoff trajectory representative of an $\mathrm{N}+2$ supersonic vehicle. The altitude of the aircraft passing the lateral microphones was $1000-\mathrm{ft}$ with a flight speed of 0.30 Mach. Single engine perceived noise levels were computed for each nozzle orientation and logarithmically summed to determine the 3-engine aircraft jet noise levels for the lateral certification point. The results for full power takeoff are shown in Fig. 12 for variations in $\mathrm{NPR}_{\mathrm{c}}, \mathrm{NPR}_{\mathrm{t}}$ and $\mathrm{A}_{\mathrm{b}} / \mathrm{A}_{\mathrm{c}}$. The cases with supersonic core velocities $\left(\mathrm{NPR}_{\mathrm{c}}=2.1\right)$ are 3.5

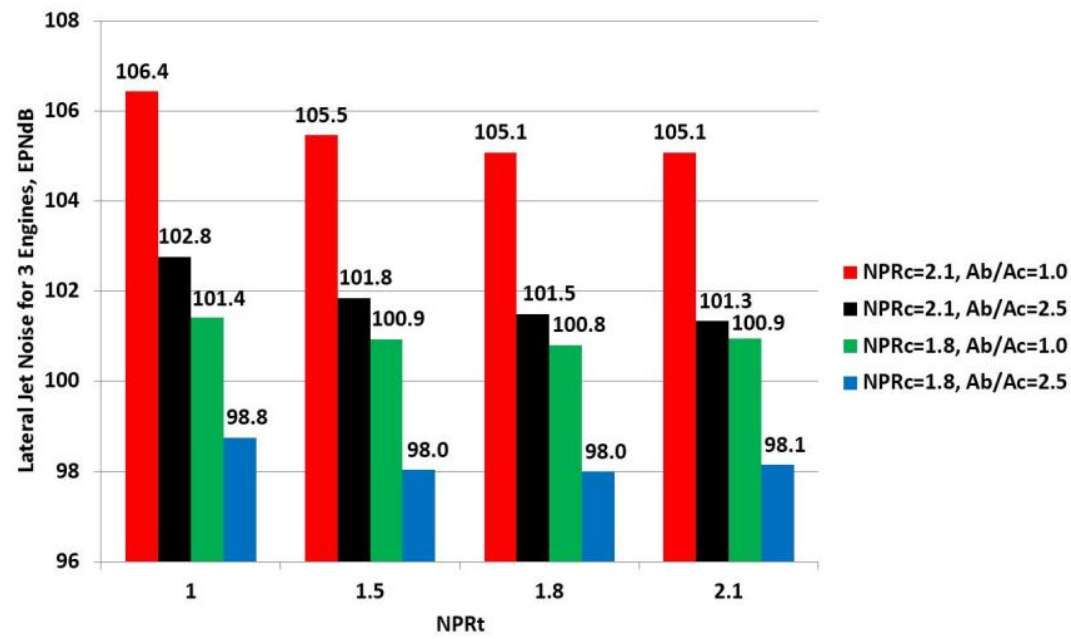

Figure 12. Perceived noise levels for 3 engines with offset nozzles on a 1044-like aircraft for selected values of NPRc, NPRt and $A_{b} / A_{c}$. to 5.0 EPNdB louder than cases with subsonic cores $\left(N P R_{c}=1.8\right)$ at a given $A_{b} / A_{c}$. The optimum $N$ PR $R_{t}$ usually occurs between 1.6 (not plotted) and 1.8. Furthermore, the noise levels are always quieter for larger $A_{b} / A_{c}$ at a specific $N_{P R}$.

The noise reduction benefits of the offset nozzle orientations shown in Fig. 11(b) can be found by comparing the various tertiary stream NPRs for a given $\mathrm{NPR}_{c}$ and $\mathrm{A}_{b} / \mathrm{A}_{\mathrm{c}}$ to the axisymmetric case when $\mathrm{NPR}_{t}=1.0$ in Fig. 12 . 
Results show that there is a 1.3 to 1.5 EPNdB benefit for $\mathrm{NPR}_{\mathrm{c}}=2.1$, and a 0.6 to $0.8 \mathrm{EPNdB}$ benefit for $\mathrm{NPR}_{\mathrm{c}}=1.8$.

The cases with $\mathrm{NPR}_{\mathrm{c}}=2.1$ are representative of higher range VCEs shown in Fig. 2. As will be shown next, these levels exceed even Chapter 3 noise regulations. For the nozzles and engines considered in this study, offset jets on a VCE do not provide enough noise reduction to be as quiet as a dual-stream MFTF with lower NPR .

The next part of the study investigates alternative takeoff procedures for noise reduction. Simulated flyovers were done for the quietest case shown in Fig. $12\left(\mathrm{NPR}_{\mathrm{c}}=\right.$ $\left.1.8, \mathrm{~A}_{\mathrm{b}} / \mathrm{A}_{\mathrm{c}}=2.5\right)$ with and without PLR. A $10 \%$ PLR, which means the takeoff power is reduced to $90 \%$ of the maximum net thrust, is considered a reasonable goal for reducing lateral noise. But this would still need to be approved by regulatory agencies for commercial flights before it can be considered as a realistic takeoff procedure. Fig. 13 shows flyover time histories for various noise metrics such as overall SPL, A-weighted SPL, PNL, and tone-corrected PNLT. The solid lines are for no PLR and the dashed lines are for $10 \%$ PLR. There is a reduction in the peak PNL of about $3 \mathrm{~dB}$ for the reduced thrust case and the falloff rate is higher. While this case is for offset nozzles with a three-stream VCE, a dualstream turbofan would have similar flyover levels based on the spectra comparisons in Fig. 7(b) for axisymmetric nozzles.

Fig. 14 summarizes the results for the two cases in terms of EPNL. Chapter 3 noise limits for the lateral certification point would be $99.3 \mathrm{EPNdB}$ for the 1044-size

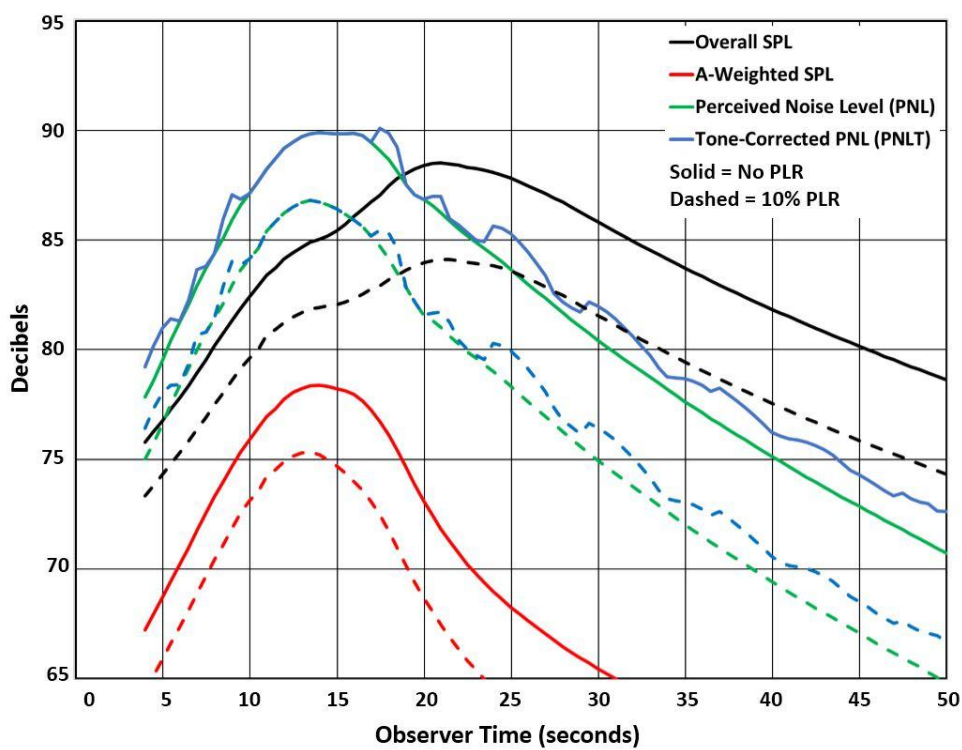

Figure 13. Single engine flyover metrics for offset nozzles, $N P R_{c}=1.8, N^{N P R_{b}}=1.8, N P R_{t}=1.6, N T R_{c}=3.0$ and $A_{b} / A_{c}=2.5$.

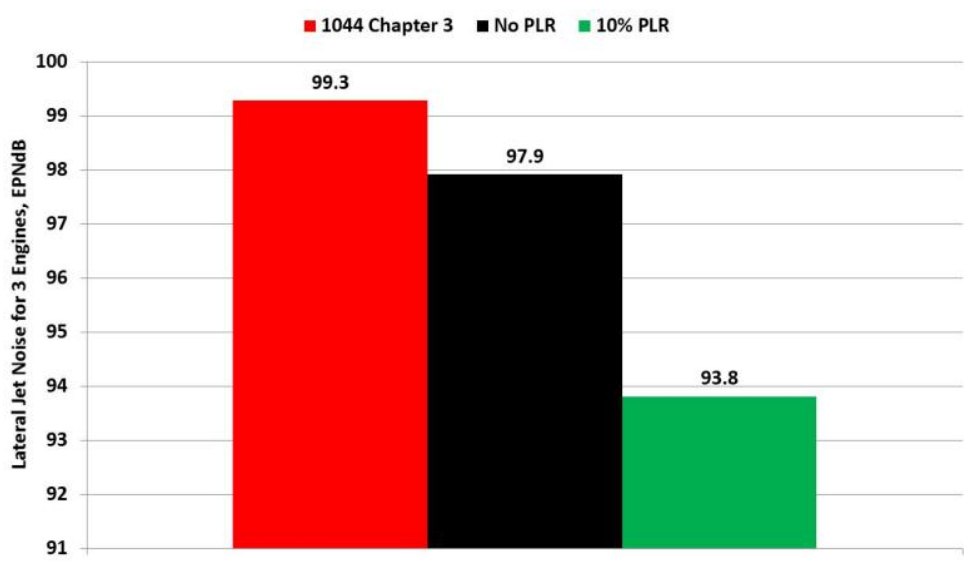

Figure 14. Effective perceived jet noise levels, three engines on 1044-like aircraft for offset nozzles, $\mathrm{NPR}_{\mathrm{c}}=1.8, \mathrm{NPR}_{\mathrm{b}}=1.8$, $\mathrm{NPR}_{\mathrm{t}}=1.6, \mathrm{NTR}_{\mathrm{c}}=3.0$ and $\mathrm{A}_{\mathrm{b}} / \mathrm{A}_{\mathrm{c}}=2.5$.

aircraft. With full throttle takeoff, there is a 1.4 EPNdB margin to Chapter 3 regulations. With a $10 \%$ PLR, the margin increases to $5.5 \mathrm{EPNdB}$. Current noise regulations are below the older Chapter 3 values. Since the estimates in this paper are for only the lateral jet noise component, it is not possible to directly compare to Chapter 4 or Chapter 14 limits as they are specified as cumulative margins across the three certification points. It is reasonable to assume that at least one-third of the noise reduction should come from each point, which would require about 5.7 EPNdB noise reduction below Chapter 3 at the lateral microphone. This means the best case evaluated for offset nozzles would almost meet Chapter 14 noise levels. It is common practice to introduce aircraft with sufficient margin below required noise levels. On a cumulative basis, it is desirable to have at least a $4 \mathrm{EPNdB}$ margin to account for uncertainties. ${ }^{18}$ If growth versions of the aircraft are introduced where the thrust requirements are achieved through a "throttle push," additional margin will be required. Therefore additional work is needed focusing on a combination of PLR and jet noise reduction technologies for low specific thrust engines to meet noise regulations. 


\section{Conclusion}

A study was conducted for a conceptual 35 to 70 passenger commercial supersonic aircraft using experimental jet noise data to predict the benefits of offset jets and alternative takeoff operating procedures to reduce jet noise. Results show there are two types of engines that provide acceptable mission range performance; one is a conventional mixed-flow turbofan and the other is a three-stream variable-cycle engine. The following overall conclusions are made from the study:

- For the engines evaluated, a VCE with three-streams and maximum mission range is predicted to have jet noise levels that are 8 to 10 EPNdB higher than a lower specific thrust dual-flow MFTF. The MFTF is predicted to have a range that is about 100 miles less than the VCE. However, the larger diameter lower expansion ratio nozzles associated with the MFTF could adversely impact sonic boom signatures.

- Separate flow, offset nozzles reduce the noise directed toward the thicker side of the outer flow stream.

- The noise reduction benefits from offset nozzles due to azithuthal directivity become less as $\mathrm{NPR}_{\mathrm{c}}$ is reduced. Results show that there is a 1.3 to $1.5 \mathrm{EPNdB}$ benefit for $\mathrm{NPR}_{\mathrm{c}}=2.1$, and a 0.6 to $0.8 \mathrm{EPNdB}$ benefit for $\mathrm{NPR}_{\mathrm{c}}=$ 1.8 .

- It is unlikely that offset nozzles will provide enough noise reduction for the highest range VCE considered in the engine parametric study to be quieter than a dual-stream MFTF with a lower NPR .

- For a three-engine N+2 aircraft with full throttle takeoff, there is a 1.4 EPNdB margin to Chapter 3 noise regulations predicted for the lateral certification point (assuming jet noise dominates). This was for the best case offset nozzle configuration with $\mathrm{NPR}_{\mathrm{c}}=1.8, \mathrm{NPR}_{\mathrm{b}}=1.8, \mathrm{NPR}_{\mathrm{t}}=1.6, \mathrm{NTR}_{\mathrm{c}}=3.0$ and $\mathrm{A}_{\mathrm{b}} / \mathrm{A}_{\mathrm{c}}=2.5$.

- With a 10\% PLR, the margin increases to 5.5 EPNdB and is sufficient to meet Chapter 4 regulations. This should also enable aircraft that can meet the new Chapter 14 noise levels (depending on the cumulative split between the three certification points). However, it is standard practice to have at least a 4 EPNdB cumulative margin in addition to whatever margin is needed to account for growth versions of the aircraft.

- Further research should focus on noise reduction technologies for low specific thrust engines applied to supersonic aircraft, including their impact on sonic boom.

\section{Acknowledgments}

This work was supported by NASA's Commercial Supersonic Technology (CST) project in the Advanced Air Vehicles Program.

\section{References}

${ }^{1}$ Huff, D.L., "NASA Glenn's Contributions to Aircraft Engine Noise Research," Journal of Aerospace Engineering, Vol. 26, No. 2, April 2013, pp. 218-250 and NASA/TP-2013-217818, 2013.

${ }^{2}$ Dickerson, N., "Aircraft Noise Technology and International Noise Standards," ICAO 2014, http://www.icao.int/SAM/Documents/2014-ENV/3.2.Noise\%20TechnologyV3_notes.pdf .

${ }^{3}$ Berton, J.J., Haller, W.J., Senick, P.F., Jones, S.M., and Seidel, J.A.; “A Comparative Propulsion System Analysis for the High-Speed Civil Transport," NASA/TM-2005-213414, 2005.

4“Critical Propulsion Components Volume 1: Summary, Introduction, and Propulsion Systems Studies," NASA/CR-2005213584, 2005.

${ }^{5}$ Hendricks, E.S. and Seidel, J.A., “A Multidisciplinary Approach to Mixer-Ejector Analysis and Design,” NASA TM-2012217709 and AIAA-2012-4224, 2012.

${ }^{6}$ Seidel, J. and Hendricks, E., "Commercial Supersonic Variable Cycle Engine Modeling with Application of Mixer-Ejector Nozzles," NASA Fundamental Aeronautics Program Technical Conference, March 2012.

${ }^{7}$ Seidel, J.A., "Discussion of 3-Stream Variable Cycle Engine Technology for Commercial Supersonic Aircraft," NASA Acoustics Technical Working Group, April 2014.

${ }^{8}$ Morgenstern, J., et al., "Advanced Concept Studies for Supersonic Commercial Transports Engine Service in the 2018-2020 Period Phase 2,” NASA CR-2015-218719, July 2015.

${ }^{9}$ Papamoschou, D. and Debiasi, M., "Directional Suppression of Noise from a High-Speed Jet,” AIAA Journal, Vol. 39, No. 3, 2001.

${ }^{10}$ Henderson, B., Leib, S., and Wernet, M., "Measurements and Predictions of Noise from Three-Stream Jets," AIAA-20153120, 2015 and NASA/TM-2015-218848, August 2015.

${ }^{11}$ International Standards and Recommended Practices - Environmental Protection, "Annex 16 to the Convention on International Civil Aviation, Volume I: Aircraft Noise," 7th Edition, International Civil Aviation Organization (ICAO), Montreal, Canada, July 2014.

${ }^{12}$ U.S. Code of Federal Regulations, Title 14, Chapter I, Part 36, "Noise standards: Aircraft Type and Airworthiness Certification."

${ }^{13}$ Gillian, R.E., “Aircraft Noise Prediction Program User’s Manual,” NASA TM-84486, 1983. 
${ }^{14}$ Zorumski, W.E., “Aircraft Noise Prediction Program Theoretical Manual, Parts 1 and 2,” NASA TM-83199, 1982; Latest revision: Level 31.

${ }^{15}$ Brown, C. and Bridges, J, "An Analysis of Model Scale Data Transformation to Full Scale Flight Using Chevron Nozzles," NASA TM-2003-212732, 2003.

${ }^{16}$ Shaw, R.J., Gilkey, S., and Hines, R., "Engine Technology Challenges for a 21st Century High-Speed Civil Transport," NASA TM-106216, 1993.

${ }^{17}$ Jackson, E.B., Raney, D.L., Glaab, L.J., and Derry, S.D., "Piloted Simulation Assessment of a High-Speed Civil Transport Configuration, "NASA TP-2002-211441, 2002.

${ }^{18}$ Huff, D.L. et al., "Report to CAEP by the CAEP Noise Technology Independent Expert Panel: Novel aircraft noise technology review and medium and long term noise reduction goals," ICAO, Doc 10017, 2014.. 